Bruce P. Kingsley MD, M. Sue Vaughan, PHD, Robert W, Vaughan MD

\title{
Cardiovascular effects of nondepolarizing relaxants employed for pretreatment prior to succinylcholine
}

A pregnant woman with severe pre-eclampsia experienced a hypertensive crisis following a pretreatment dose (20 $\mathrm{mg}$ ) of gallamine. That episode initiated a study to determine the cardiovascular effects of non-depolarizing muscle relaxants in 58 nonobese, ASA physical status $I$ and II adults. Subjects were assigned randomly to one of five treatment groups as follows: gallamine $\left(0.29 \mathrm{mg}-\mathrm{kg}^{-1}\right), d$-rubocurarine $\left(0.04 \mathrm{mg}-\mathrm{kg}^{-1}\right)$, metocurine $\left(0.014 \mathrm{mg} \cdot \mathrm{kg}^{-1}\right)$, pancuronium $\left(0.007 \mathrm{mg} \cdot \mathrm{kg}^{-1}\right)$, or normal saline (control). Baseline measurements of systolic, diastolic, mean arierial pressure, heart rate $(H R)$ and rate pressure product (calculated $R P P$ ) were recorded at one-minute intervals while electrocardiogram, lead $I$, was recorded continuously. Statistically significant increases occurred in HR at minutes 2, 3 and 4; RPP at minutes 3 and 4 ; and per cent change in $H R$ at minutes 2,3 and 4 following gallamine pretreatment. The rise in RPP was predominately due to the elevation in $H R$. These results suggest that even modest doses of gallamine should be avoided in clinical situations where lability of cardiovascular aynamics can be anticipated.

\section{Key words}

NEUROMUSCULAR BLOCKING DRUGS: d-tubocurarine, gallamine, metocurine, pancuronium, succinylcholine.

From the Department of Anesthesiology, Arizona Health Sciences Center, Tucson, Arizona.

Address correspondence to: R.W. Vaughan MD, Department of Anesthesiology, University of North Carolina School of Medicine, Chapel Hill, N.C. 27514.
Subparalyzing, pretreatment doses of nondepolarizing muscle relaxants are widely employed in the induction period to limit the adverse effects of succinylcholine. These modest doses of nondepolarizing muscle relaxants can limit changes in intragastric ${ }^{1,2}$ and intraocular pressures, ${ }^{3}$ serum potassium, ${ }^{4}$ creatine kinase, ${ }^{5}$ the incidence of postoperative myalgias, ${ }^{6}$ and the bradycardia associated with a repeat dose of succinylcholine ${ }^{7,8}$ Although controversial and recently challenged, ${ }^{9}$ "pretreatment" has become an accepted part of the rapid induction-intubation sequence for general anaesthesia, particularly for the patient with a full stornach. ${ }^{10}$

\section{Case Summary}

A 38-year-old primagravida at 30 weeks' gestation required emergency Cesarean section for severe pre-eclampsia complicated by progressive reduction in platelet count. There was no history of previous anaesthetics, major illnesses, or adverse reactions to medications. The patient had been taking alpha-methyl dopa and hydrochlorthiazide for blood pressure control. Physical examination revealed: weight, $66 \mathrm{~kg}$; blood pressure, $220 / 110$ torr; pulse, 84 beats/minute; temperature, $37.0^{\circ} \mathrm{C}$ orally; respiration, 16 per minute. The upper airway and the cardiopulmonary systcm wcre judged normal. Pitting edema $(2+/ 4+)$ of the lower extremities and sustained ankle clonus were demonstrated. Laboratory results were: haemoglobin $15.6 \mathrm{gm} / \mathrm{dl}$, serum potassium $4.1 \mathrm{mEq} / \mathrm{L}$, blood urea nitrogen $28 \mathrm{mg} / \mathrm{dl}$, serum creatinine $1.3 \mathrm{mg} / \mathrm{dl}$, and a normal coagulation profile with the single exception of a 
platelet count of $17,000 / \mathrm{mm}^{3}$. No urine was obtainable for analysis.

The patient was placed in a quiet room with subdued lighting. Using local anaesthesia, a peripheral intravenous cannula was inserted, a loading dose of magnesium sulfate $(4 \mathrm{Gm})$ administered and a continuous infusion initiated. Using local anaesthesia, a teflon 20 gauge $1 \frac{1}{2}$ " cannula was inserted into the left radial artery at the wrist and attached to a pressure transducer. Using the same technique, a central venous cannula was inserted via the left antecubital vein. Initial readings were a blood pressure of $220 / 110$ torr and central venous pressurc (CVP) of -5 torr. Rapid hydration was begun until the CVP approached normal levels. The patient was taken to the operating room where her blood pressure was controlled (160/80 torr) with sodium nitroprusside $\left(1 \mu \mathrm{g} \cdot \mathrm{kg}^{-1} \cdot \mathrm{min}^{-1}\right)$. Subsequently anaesthetic induction was begun. After the patient received oxygen by mask for five minutes, gallamine $(20 \mathrm{mg})$ was given into the peripheral intravenous infusion. The pulse rate immediately increased from 90 to 130 and the blood pressure increased from $160 / 95$ to $230 / 115$. This hypertensive response was unchanged by increasing the nitroprusside infusion to approximately $4 \mu \mathrm{g}$. $\mathrm{kg}^{-1} \cdot \mathrm{min}^{-1}$. Anaesthetic induction proceeded with sodium thiopentone $(200 \mathrm{mg})$ while skeletal muscle relaxation was acomplished with succinylcholine (100 mg). When the lash reflex was lost following thiopental, cricoid pressure was applied and the larynx was intubated with a cuffed endotracheal tube. Following induction and intubation, the blood pressure decreased to $200 / 90$. Six minutes after induction of anaesthesia a viable infant was delivered, the placenta manually removed, and the nitroprusside infusion discontinued. The BP slowly decreased to $100 / 60$. The remainder of the case was uneventful. The mother and child were followed for 48 hours and no sequelae were observed.

\section{Comment}

The cardiovascular and autonomic side effects of paralyzing doses of nondepolarizing neuromuscular blockers have been extensively examined. For example, in anaesthetized patients, paralyzing doses of gallamine result in increases in heart rate and cardiac output secondary to the muscarinic blocking, chronotropic actions of the drug. " The cardiovascular effects of these drugs in pretreat- ment doses have been presumed to be innocuous. However, their effects have not been examined within a controlled experimental (control group, randomization, double blinded) design. The importance of considering the cardiovascular effects of these small doses was the subject of a recent editorial. ${ }^{12}$ To evaluate this question we performed a prospective, randomized, blinded clinical trial.

\section{Methods}

Following protocol approval by the institurional Human Subjects Committee, vebal and written consent was obtained from 58 subjects on the evening prior to operation. ASA physical status 1 and II patients scheduled for elective surgical procedures under general anaesthesia were chosen for study. Subjects excluded from the clinical trial were those who were obese (body mass index $>$ $\left.30 \mathrm{~kg} / \mathrm{m}^{2}\right){ }^{1,3}$ allergic to iodine or bromide, or receiving adrenergic blocking drugs. All patients were fasted after midnight and no patient received overnight intravenous hydration. Both preoperative medications and preoxygenation were withheld. Patients were assigned, using a table of random numbers, to one of five pretreatment groups as follows: gallamine $\left(0.29 \mathrm{mg} \cdot \mathrm{kg}^{-1}\right)$, d-tubocurarine $\left(0.04 \mathrm{mg} \cdot \mathrm{kg}^{-1}\right)$, metocurine $\left(0.014 \mathrm{mg} \cdot \mathrm{kg}^{-1}\right)$, pancuronium $\left(0.007 \mathrm{mg} \cdot \mathrm{kg}^{-1}\right)$, or normal saline (control). The tutal volume of the pretreatment agent was adjusted to one $\mathrm{ml}$ prior to injection.

Upon arrival in the operating room holding area, an intravenous cannula was placed and the patient transported to the operating suite where blood pressure (BP), electrocardiogram (EKG), and chest stethoscope monitors were applied. An automated oscillometric technique (Sentry) was employed to measure systolic (SBP), diastolic (DBP), and heart rate (HR) as well as calculate mean arterial pressure (MAP). Subsequent calculations included rate pressure product (HR times SBP) and per cent change from baseline of HR and RPP. Lead II of the EKG was recorded continuously.

All cardiovascular measurements were recorded by a knowledgeable, blinded clinical investigator (MSV). The same anaesthesiologist (RWV) administered all pretreatment drugs and induction agents. The other investigator (BPK), blinded to patient variables and assigned pretreatment group, evaluated all EKG recordings for presence and timing of dysrhythmias. 
TABLE I Descriptive characteristies of the sample by treatment group* (mean $=$ SE)

\begin{tabular}{lccccc}
\hline & Gallamine & DTC & MTC & PCB & NS \\
\hline Number of patients & 10 & 13 & 12 & 12 & 11 \\
Age (yrs) & $39 \pm 5$ & $32 \pm 3$ & $41 \pm 5$ & $38 \pm 4$ & $45 \pm 5$ \\
Weight (kg) & $71 \pm 8$ & $59 \pm 3$ & $63 \pm 3$ & $69 \pm 3$ & $68 \pm 5$ \\
Height (cm) & $167 \pm 5$ & $162 \pm 2$ & $165 \pm 2$ & $168 \pm 2$ & $166 \pm 3$ \\
\hline
\end{tabular}

${ }^{*} p>0.05$ among groups.

\$Abbreviations: DTC $=$ d-tubocurarine, $\mathrm{MTC}=$ metocurine, $\mathrm{PCB}=$ pancuronium, $\mathrm{NS}=$ nomal saline.

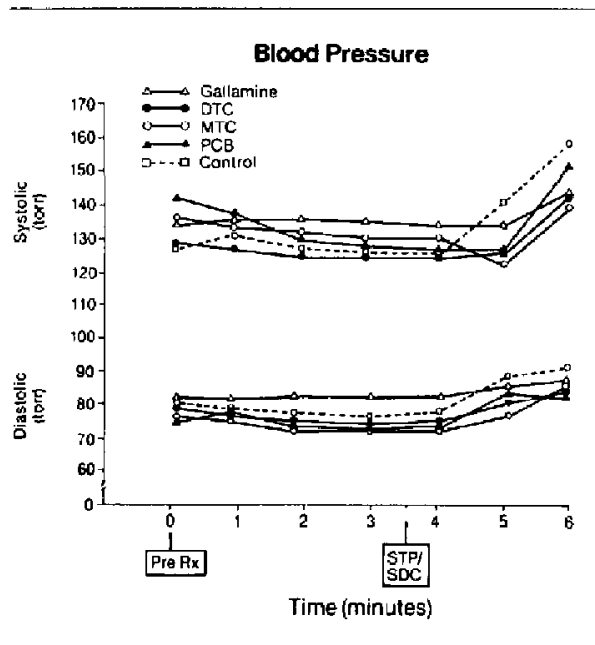

FIGURE 1 Systolic and diastolic blood pressure in pretreatment groups and control. No significant difference accumed among groups at any time interval $(p>0.05)$.

Once baseline measurements of cardiovascular variables (SBP, DBP, MAP, HR, continuous EKG recording) were completed, pretreatment drug or control (normal sajine) was administered. Cardiovascular measurements were recorded at one minute intervals for six minutes. At 3.5 minutes after pretreatment, induction commenced with sodium thiopentone $\left(4 \mathrm{mg} \cdot \mathrm{kg}^{-1}\right)$ and succinylcholine $(1.5$ $\mathrm{mg} \cdot \mathrm{kg}^{-1}$ ) injected intravenously over a 20 - to 30 -second interval. At minute five, ventilation was controlled by mask with 100 per cent oxygen. Following oxygenation, patients requiring an endotracheal tube were intubated while airway management for other patients was by mask without laryngoscopy. Measurement of cardiovascular variables at minute six concluded the study.

Results were analyzed using a one-way analysis of variance and the Tukey-B multiple range test for interpretation of differences among groups. In addition, Chi-square analysis was used to test differences among groups for incidence of dysrhythmias. Statistical significance was set at $\mathrm{p} \leq 0.05$.

\section{Results}

Fifty-eight adult subjects, 12 males and 46 females, were studied. Descriptive characteristics for the total sample included (mean $\pm \mathrm{SE}$ (range)): age, 39 \pm 2 years $(19-84)$; weight, $66 \pm 2 \mathrm{~kg}(41-127)$; and height, $165 \pm 1.3 \mathrm{~cm}(147-201)$. There was no difference among the pretreatment groups with respect to age, weight, height (Table I), medication history, allergies, or smoking history. Of the 35 patients requiring intubation, eight were intubated just prior to minute six and 27 were intubated after the study concluded. No significant difference occurred among the treatment groups with respect to those intubated between minutes five and six. Medication history revealed that 51 subjects received no medication while seven were intermittently taking sedatives (3), diuretics (2), or chemotherapeutic drugs (2). No significant differences among groups in baseline cardiovascular variables were present. In addition, neither SBP nor DBP differed significantly among groups at any time interval (Figure 1). In contrast, the group given gallamine pretreatment developed a significant increase in HR at minutes two, three, and four (Figure 2). Subsequent mask ventilation during light nitrous oxide-barbiturate anaesthesia resulted in persistent increases in $\mathrm{HR}$ during the study period. In addition, calculated RPP also was significantly elevated in the gallamine group when compared with the 


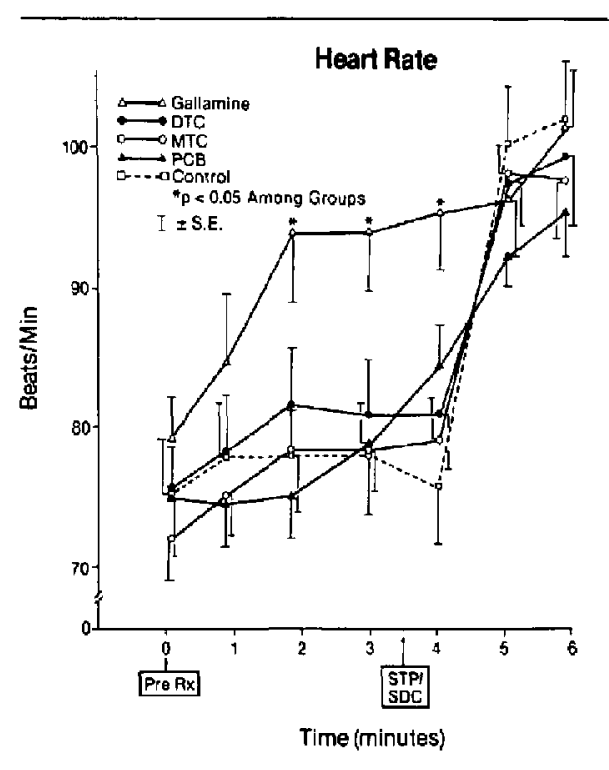

FIGURE 2 Hcar rate (mean $\pm S E$ ) in pretreatment groups and control. A significant increase in rate occurred in the gallamine group at minutes two, threc, and four $(p<0.05)$.

other groups at minutes three and four following pretreatment nondepolarizer (Figure 3). When change in HR following pretreatment drugs was calculated as percent of baseline, patients receiving gallamine demonstrated a maximum change of 20 per cent that was significantly greater than all other groups at minutes two, three and four (Figure 4). Other treatment groups were not significantly different from each other with respect to SBP, DBP, MAP, RPP or HR.

Dysrhythmias, after succinylcholine but prior to intubation, occurred in seven of 58 subjects (12.1 per cent: (Table I)). Rhythm disturbances were characterized as nodal ( $\mathrm{n}=1)$, premature atrial contractions greater than five per minute $(n=4)$, premature ventricular contractions greater than five per minute $(n=2)$, and atrial bigeminy $(n=1)$. One patient experienced both premature atrial and ventricular contractions. Five subjects experienced dysthythmias prior to laryngoscopy, one after, and one dysthythmia occurred at minute six in a nonintubated subject. There was significant difference in EKG changes between patient groups.

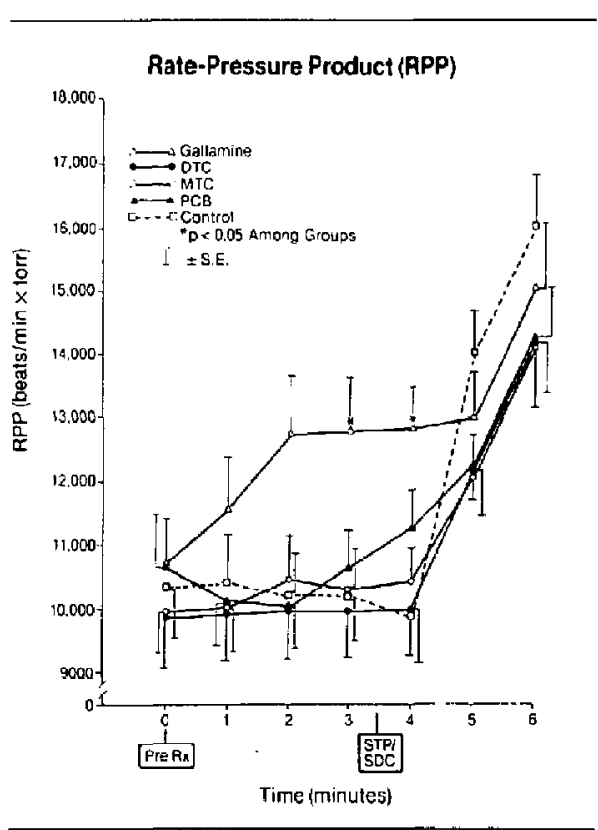

FIGURE 3 Rate pressure product (mean $\pm S E$ ) in pretreatment groups and control. A significant elcvation occurred in the gallamine group at minutes threc and four $(p<0.05)$.

\section{Discussion}

Undesirable tachycardia and arterial hypertension can occur in the operative patient following neuromuscular paralyzing doses of nondepolarizing skeletal muscle relaxants. ${ }^{14,15}$ Animal studies suggest that the effects of tachycardia after administration of gallamine result in part from release of norepinephrine from cardiac adrenergic postganglionic nerve endings. ${ }^{16}$ Although other investigators conclude that heart rate and arterial pressure changes in cats given $1.2 \mathrm{mg} \cdot \mathrm{kg}^{-1}$ and $1.5 \mathrm{mg} \cdot \mathrm{kg}^{-1}$ doses of gallamine are minimal, neuromuscular blocking agents which cause vagal blockade do not produce such a marked degree of tachycardia in cats, dogs, and monkeys as they do in man. It appears that normal vagal tone is less in these animal species. ${ }^{17}$ Descriptive studies in man further suggest partial blockade of muscarinic receptors in vagally innervated cardiac muscle. " As tachycardia develops, cardiac output and blood pressure increase concomitant with mild decrease in systemic peripheral vascular resistance (SVR). ${ }^{15} \mathrm{Hy}$ - 


\begin{tabular}{|c|c|c|c|c|c|}
\hline & \multicolumn{5}{|l|}{ Groups } \\
\hline & Gallamine & DTC ${ }^{*}$ & $M T C$ & $P C B$ & $N S$ \\
\hline \multicolumn{6}{|c|}{ Cardiac rhythm ${ }^{+}$} \\
\hline Abnormal & $1 \neq$ & 3 & 0 & 0 & 3 \\
\hline Normal & 9 & 10 & 12 & 12 & 8 \\
\hline
\end{tabular}

*Abbreviations: DTC $=$ d-tubocurarine. $\mathrm{MTC}=$ metocurine, $\mathrm{PCB}=$ pancuronium,

$\mathrm{NS}=$ normal saline.

$\dagger p>0.05$ among groups.

$\ddagger$ Number of dysrhythmias.

pertension following gallamine relaxation may be related to increased endogenous cardiac stores of norepinephrine or failure of the moderating decrease in SVR.

Several studies have described tachycardia in operative patients after gallamine dosages of 0.5 $1.0 \mathrm{mg} \cdot \mathrm{kg}^{-1}$ and $0.3 \mathrm{mg} \cdot \mathrm{kg}^{-1}{ }^{15.18}$ However, study design limitations do not allow cause-effect determinations. For example, Viby-Mogensen et al. in a comparative study in adults described the effect of a second dose of suxamethonium after preinduction (three minutes before induction) administration of atropine, gallamine or an intravenous combination. ${ }^{18}$ All patients in the four treatment groups received premedication with diazepam $(0.1$ $\mathrm{mg} \cdot \mathrm{kg}^{-1}$ ) one hour before induction. A control group (i.e., no treatment) was absent. A cause (gallamine) - effect (tachycardia) relationship could not be established. Factors further limiting interpretation of results included potential interaction of preanaesthetic medications with muscle relaxants, unblinded observations, and potential confounding variables (i.c., patient anxicty, face mask preoxygenation, manipulation of upper airway). Diazepam serves to illustrate the latter problem with confounding variables and the necessity to control each. For example, it is well accepted that diazepam absorption following an intramuscular dose is dependent on site of injection, the patient's body habitus, per cent body fat, and kenetics of drugs distribution. Uniform absorption, distribution, and biotransformation cannot be assumed. Our study design was experimental and prospective in nature utilizing random assignment with a random numbers table. Extraneous variables such as preoperative medication and preoxygena-

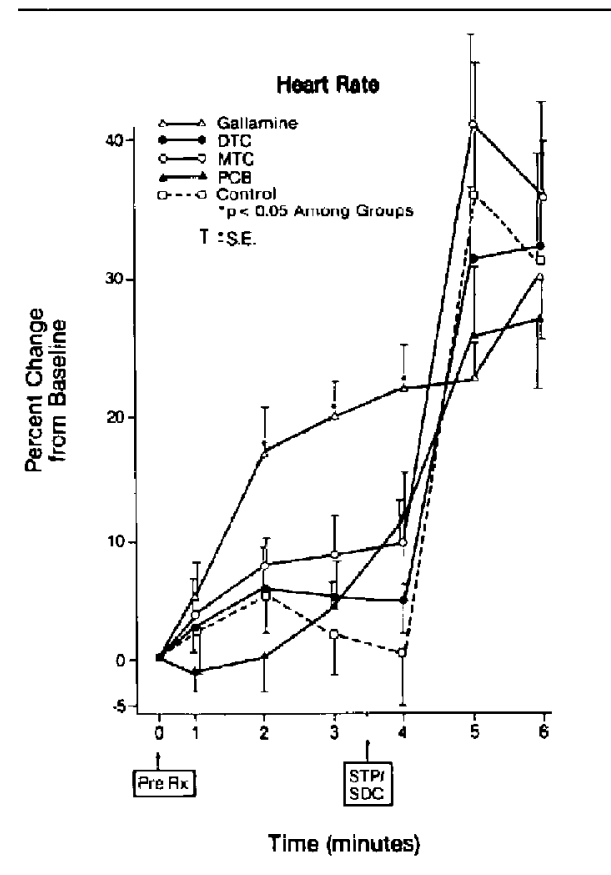

FIGURE 4 Per cent change in heart rate (mean $\pm S E$ ) in pretrcatment groups and control. A significantly greater per cent change occurred in the gallamine group at minutes two, three, and four $(p<0.05)$.

tion were eliminated to avoid confounding the recorded cardiovascular effects after pretreatment drug administration. Further, treatment groups were compared to control (normal saline) while employing double blinded observers strengthened 
the research design. A cause-effect relationship can now be concluded and clinical care altered.

Dysrhythmias (Table II) were evident in a certain per cent of study patients. EKG changes occurred after pretreatment and succinylcholine administration but before laryngoscopy and intubation. No patient experienced serious or continuous nodal changes, premature atrial contractions, or premature ventricular contractions requiring therapy.

No significant increase in systolic or diastolic blood pressures occurred among study groups. This contrasts with the bypertensive crisis experienced by our case study patient. However, that patient manifested pre-eclampsia with apparent constricted blood volume and concomitant labile cardiovascular dynamics. Patients in the research groups were not pre-eclamptic hypertensives, and met the criteria for ASA I or II classification.

Finally, significant changes occurring after minute 3.5 in our study are undoubtedly due to interactive effects of sodium thiopentone and succinylcholine. The effects of nondepolarizing relaxants would likely be masked at minute four by such confounding, interactive effects. In conclusion, our controlled, clinical trial demonstrated a statistically significant increase in heart rate and RPP following even a small pretreatment dose $\left(0.29 \mathrm{mg}-\mathrm{kg}^{-\mathrm{J}}\right)$ of gallamine when contrasted to other nondepolarizing relaxants and control. The cardiovascular effects of gallamine appear to occur even in these minimal doses, suggesting that the drug is unsuitable for use in patients with an increased or fixed SVR, such as an individual with pre-eclampsia.

\section{References}

1 Miller $R D$, Way $W L$. Inhibition of succinylcholineinduced increased intragastric pressure by nondepolarizing muscle relaxants and lidocaine. Anesthesiology 1971; 34: 185-8.

2 Murawchick S, Burkeit L, Gold MI. Succinylcholine-induced faciculations and intragastric pressure during induction of anesthesia. Anesthesiology 1981; 55: 180-3.

3 Miller RD, Way WL, Hickey RF. Inhibition of succinylcholine-induced intraocular pressure by nondepolarizing muscle relaxants. Anesthesiology 1968; 29: 123-6.

4 Birch AA, Mitchell GD, Playford GA, Lang CA. Charges in serum potassium response to succinyl- choline following trauma. JAMA 1969; 210: 490-3.

5 Tammisto $T$, Leikkonen $P$, Airaksinen $M$. The inhibitory effect of d-tubocurarine on the increase of serum creatine-kinase activity produced by intermittent suxamethonium administration during halothane anaesthesia. Acta Anesthesiol Scand 1967; 11: 333-40.

6 Lamoreaux $L F$, Urback $K F$. Incidence and prevention of muscle pain following the administration of succinylcholine. Anesthesiology 1960;21: 394-6.

7 Stoelting RK, Peterson C. Adverse effects of increased succinylcholine dose following d-tubocurarine pretreatment. Anesth Analg 1975; 54: 282-8.

8 Stoelting $R K$, Peterson $C$. Heart-rate slowing and junctional rhythm following intravenous succinylcholine with and without intramuscular atropine preanesthetic medication. Anesth Analg 1975; 54: $705-9$.

9 Brodsky $J B$. Why routinely pretreat? Anesthesiology 1982; 56: 488-9.

10 Giesecke AH. Anesthesia. New York: Churchill Livingstone, 1981.

11 Eisele JH, Marta JA, Hamilton SD. Quantitative aspects of the chronotropic and neuromuscular effects of gallamine in anesthetized man. Anesthesiology $1971 ; 35: 630-3$.

12 Madell JH. Survey of Anesthesiology 1982; 26: 262.

13 Bray GA, Jordan HA, Sims EAH. Evaluation of the obese patient. 1. An algorithm. JAMA 1971; 235: $1487-91$.

14 Doughy $A G$, Wylie WD. An assessment of flaxedil (gallamine triethiodide. B.P.). Proc Royal Soc Med 1951; 44: 375-86.

15 Kennedy BR, Farman $J V$. Cardiovascular effects of gallamine triethiodjde in man. Br J Anaesth 1968; 40: $773-9$.

16 Brown $B R$, Crout $R J$. The sympathomimetic effect of gallamine on the heart. J Pharmacol Exp Ther 1970; 172: 266-73.

17 Hughes R, Chapple DJ. Effects of non-depolarizing neuromuscular blocking agents on peripheral autonomic mechanisms in cats. Br J Anaesth 1976; 48: 59-67.

18 Viby-Mogensen $J$, Wisborg $K$, Sorensen $O$. Cardiac effects of atropine and gallamine in patients receiving suxamethionium. $\mathrm{Br} \mathrm{J}$ Anaesth 1980; 52: $1137-$ 42. 


\section{Résumé}

Une femme enceinte souffrant de pré-èclampsie sêvère a prêsenté une crise hypertensive à la suite d'un pré-traitement à la galamine $(20 \mathrm{mg}$ ). Cet incident est à la source de ce travail qui a étudié les effets cardio-vasculaires des myo-résolutifs non dépolarisants employés pour prévenir les douleurs causées par la succinylcholine. Naus avons étudiê 58 adultes nor-obèses, d'état physique $I$ et 2 de I'A.S.A.

Chaque sujet a été assigné au hasard à un de cinq groupes différents: galamine $0.29 \mathrm{mg} \cdot \mathrm{kg}^{-1}$, détubocwrarine $0.04 \mathrm{mg} \cdot \mathrm{kg}^{-1}$, méthocurine $0.014 \mathrm{mg} \cdot \mathrm{kg}^{-1}$, panduronium $0.007 \mathrm{mg}^{\prime} \mathrm{kg}^{-1}$ et solutés salins pour une groupe contrôle.

Les mesures de controble: pression systolique, diastolique et moyenne, la fréquence cardiague et produit fréquencelpression ont été enregistrés à une mintute d'intervalle alors que l'électrocardiogramme en dérivation etait inscrit de façon continue. Dans le groupe recevant de la galamine, on a observé des augmentations statistiquement significatives de la fréquence cardiaque d deux, trois et quatre minutes, du RTP à trois et quatre minutes; de même le changement de la fréquence cardiaque demeurait statistiquement significatif lorsqu' exprimé en pourcentage de changement aux minutes deux. trois et quatre. L' ́lévation du RPT était en partie due à laugmentation de la fréquence.

Ces résultats suggèrent que ton devrait s'abstenir de' la galamine même à dose modeste dans les situations cliniques ou on soupçonne une instabilité cardiovasculaire. 